ISSN 1980-5098

\title{
ANÁLISE DA INFLUÊNCIA LUMINOSA NOS ASPECTOS ANATÔMICOS DE FOLHAS DE Theobroma speciosum WILLD EX SPRENG. (MALVACEAE)
}

\author{
ANALYSIS OF THE LUMINOSITY ON THE ANATOMICAL ASPECTS OF Theobroma speciosum \\ WILLD. EX SPRENG. (MALVACEAE) LEAVES
}

\author{
Juliana de Freitas Encinas Dardengo ${ }^{1}$ Ana Aparecida Bandini Rossi ${ }^{2}$ Ivone Vieira da Silva ${ }^{2}$ \\ Marcos José Gomes Pessoa ${ }^{3}$ Carolina Joana da Silva ${ }^{4}$
}

\begin{abstract}
RESUMO
O conhecimento anatômico de espécies do gênero Theobroma é importante para o estabelecimento e manutenção de coleções de germoplasma, tendo em vista estudos agronômicos e fitopatológicos e programas de melhoramento genético. Este estudo objetivou caracterizar a anatomia das folhas de Theobroma speciosum, registrando as diferenças estruturais observadas entre folhas de sol e folhas de sombra. Folhas de indivíduos de Theobroma speciosum foram coletadas no Parque Nacional do Juruena e em pastagens na zona rural do município de Alta Floresta - MT. Foram analisados a espessura do mesofilo foliar, dos parênquimas paliçádico e lacunoso, da nervura mediana e do feixe vascular. A análise de agrupamento foi realizada utilizando o método Hierárquico UPGMA, com base na distância euclidiana média padronizada. Foram observados tricomas glandulares do tipo claviforme e estrelados sésseis. A epiderme é unisseriada, o mesofilo é dorsiventral, entretanto os parênquimas são pouco distintos. Feixes vasculares colaterais estão dispersos no mesofilo, formando bainhas que se estendem até as epidermes. A nervura central, em secção transversal, possui formato biconvexo, com sistema vascular fechado envolto por bainha esclerenquimática. A constituição do mesofilo das folhas variou com o ambiente. Plantas expostas a pleno sol apresentam células mais alongadas no parênquima paliçádico, parênquima lacunoso com mais camadas e maior quantidade de tricomas, enquanto que as folhas de sombra apresentaram células com muitos espaços intercelulares no mesofilo. O dendrograma mostrou a formação de dois grupos distintos: o grupo I composto pelas plantas do Parque e o grupo II pelas plantas das pastagens. Tal agrupamento demonstrou alterações anatômicas significativas ocasionadas pelas variações da intensidade luminosa sobre as folhas, o que evidenciou grande capacidade adaptativa de Theobroma speciosum.
\end{abstract}

Palavras-chave: Cacauí; Amazônia; Mesofilo.

\section{ABSTRACT}

The anatomical knowledge of species of the Theobroma genus is important for the establishment and maintenance of germplasm collections, considering agronomic and phytopathological studies, and breeding programs. This study aimed to characterize the anatomy of Theobroma speciosum leaves, recording the structural differences observed between sun and shade leaves. Theobroma speciosum leaves were collected at Juruena National Park and in pastures in the rural municipality of Alta Floresta - MT. We analyzed the

1 Bióloga, MSc., Doutoranda em Biodiversidade e Biotecnologia da Amazônia Legal, Projeto Conhecimento, Uso Sustentável e Bioprospecção da Biodiversidade na Amazônia Meridional, Av. Perimetral Rogério Silva, s/n, CEP 78580-000, Alta Floresta (MT), Brasil. ju_kk@hotmail.com

2 Bióloga, Dra., Professora adjunta da Faculdade de Ciências Biológicas e do Programa de Pós Graduação em Biodiversidade e Agroecossistemas Amazônicos, Universidade do Estado de Mato Grosso, Av. Perimetral Rogério Silva, s/n, CEP 78580-000, Alta Floresta (MT), Brasil. anabanrossi@gmail.com / ivibot@hotmail.com

3 Biólogo, MSc., Professor contratado da Faculdade de Ciências Biológicas, Universidade do Estado de Mato Grosso, Av. Perimetral Rogério Silva, s/n, CEP 78580-000, Alta Floresta (MT), Brasil. marcos-af@hotmail.com

4 Bióloga, Dr ${ }^{\mathrm{a}}$., Professora Adjunta da Universidade do Estado de Mato Grosso, Centro de Pesquisa de Limnologia, Biodiversidade e Etnobiologia do Pantanal, Av. Tancredo Neves, CEP 78200-000 Cáceres (MT), Brasil. ecopanta@terra.com.br

Recebido para publicação em 23/05/2014 e aceito em 26/02/2016

Ci. Fl., v. 27, n. 3, jul.-set., 2017 
thickness of the leaf mesophyll, palisade and spongy parenchyma, midvein and vascular bundle. Cluster analysis was performed using the Hierarchical UPGMA method, based on the standardized mean Euclidean distance. Were observed glandular trichomes, claviforme type and sessile stellate, the epidermis is uniseriate in cross section, the mesophyll is dorsiventral, however the parenchymas are little different. Collateral vascular bundles are dispersed in the mesophyll, forming sheaths that extend up to the epidermis. The midvein, in cross section, has a biconvex shape, with closed vascular system surrounded by sclerenchymatic sheath. The constitution of the leaves mesophyll varied with the environment. Plants exposed to full sunlight showed longer cells in the palisade parenchyma, spongy parenchyma with more layers and higher quantity of trichomes, whereas shade leaves showed cells with many mesophyll intercellular spaces. The dendrogram showed the formation of two distinct groups: group I comprises the plants of the Park and group II pasture plants. The clustering showed significant anatomical changes caused by variations of light intensity on leaves, which revealed a large adaptive capacity of Theobroma speciosum.

Keywords: Cacauhy; Amazonia; Mesophyll.

\section{INTRODUÇÃO}

As causas do desmatamento acelerado na Amazônia são várias e incluem a expansão da atividade pecuária, da agricultura de corte e queima, da extração madeireira e da agricultura comercial (FEARNSIDE, 2001). Segundo Laurance e Vasconcelos (2009), uma consequência direta e inevitável do desmatamento é a fragmentação florestal, que ocorre à medida que uma grande extensão de floresta é subdividida e diminui de tamanho.

Os estudos disponíveis indicam que a fragmentação florestal causa uma diversidade de efeitos, alterando o tamanho e a dinâmica das populações, a composição e a dinâmica das comunidades, as interações tróficas e os processos ecossistêmicos (LAURANCE; VASCONCELOS, 2009).

Diante disto, várias espécies típicas de sub-bosque estão ocorrendo em locais com alta incidência luminosa, em pastagens, como é o caso da espécie Theobroma speciosum. Quando se trata de intensidade luminosa, é importante levar em consideração as variações na estrutura foliar, pois, este é o órgão da planta que mais responde anatomicamente às variações luminosas de um determinado habitat (DICKISON, 2000).

As condições de solo, água, luz e temperatura influenciam no desenvolvimento e produtividade das plantas, muitas expostas à alta intensidade luminosa e, por mutações, adquirem mecanismos morfológicos e fisiológicos que possibilitam sua sobrevivência (SILVA; ALQUINI; CAVALLET, 2005). Esses mecanismos compreendem, na folha, principalmente, a redução do tamanho, capacidade de enrolamento, alta densidade de tricomas, estômatos profundos, acúmulo de mucilagem e outros metabólitos secundários e aumento da compactação do mesofilo (BOSABALIDIS; KOFIDIS, 2002). Assim, a intensidade de luz promove alterações na estrutura das folhas, resultando em folhas denominadas folhas de sol e folhas de sombra (CUTTER, 1978).

De acordo com Boeger e Wisniewski (2003), as folhas de sol apresentam características xeromórficas, oriundas de uma maior intensidade luminosa, menor disponibilidade de água e nutrientes no solo ou mesmo pela baixa temperatura. As características observadas nessas folhas são a presença de abundante cutícula, paredes celulares mais espessas, endoderme mais espessa, além de se verificar folhas pequenas e compactas, parênquima paliçádico mais desenvolvido que o parênquima lacunoso, grande frequência de estômatos, e algumas vezes, células menores e abundante esclerênquima. Geralmente, estas características não são observadas em folhas de sombra por receberem uma menor intensidade luminosa (CUTTER, 1978).

Theobroma speciosum Willd. ex Spreng. (cacauí) está entre as espécies silvestres do gênero Theobroma e ocorre em toda a Amazônia brasileira. A espécie é importante por representar uma possível fonte de genes de resistência para outras espécies do gênero mais importantes economicamente. Dentro do gênero, é a que apresenta teor de gordura da semente mais parecido com o do cacaueiro, sendo um sucedâneo potencial (SANTOS, 2003).

O cacauí é uma árvore de 8 a 14 metros, dotadas de copa estreita e rala, sendo suas folhas simples, alternas, dísticas, pecioladas e inteiras. O fruto apresenta casca levemente aveludada, de cor amarela quando maduro, possuindo cerca de 20 sementes imersas numa polpa suculenta, muito consumida por mamíferos de médio porte, tais como macacos (LORENZI, 2000). 
O conhecimento anatômico de espécies de Theobroma torna-se útil para o estabelecimento e manutenção de coleções de germoplasma. Tais informações fornecem subsídios a estudos agronômicos, fitopatológicos e a programas de melhoramento genético (GARCIA, 2012). Entretanto, estudos anatômicos referentes às espécies pouco exploradas economicamente, como o cacaú são escassos, constando na literatura apenas trabalhos referentes às sementes (SANTOS, 2003; MARTINI et al., 2008).

$\mathrm{O}$ entendimento das relações anátomo-ecológicas ocorrentes nos vegetais, é uma das principais abordagens para o conhecimento do grau de adaptação das espécies aos nichos ecológicos ou de seus comportamentos sob condições ambientais extremas (LUTTGE, 1997). Para entender as estratégias adaptativas das plantas nos seus distintos estádios na dinâmica da floresta tropical e considerando também à contínua devastação, são necessárias a elaboração e execução de projetos de recuperação.

Os projetos devem estar embasados em informações obtidas a partir de estudos sistematizados das características do ambiente e das espécies vegetais que poderão colonizar áreas a serem recuperadas. A ausência de estudos envolvendo espécies vegetais tropicais, especialmente arbóreas, com respeito às variações morfoanatômicas e fisiológicas de folhas provocadas pelas condições distintas de luminosidade, evidencia a necessidade de um quadro de informações científicas, que poderá subsidiar os projetos de reflorestamento (SILVA; ALQUINI, Y.; CAVALLET, 2005).

Assim, este trabalho teve por objetivo caracterizar a anatomia das folhas de Theobroma speciosum, registrando as diferenças estruturais observadas em exemplares localizados em pastagem (folhas de sol) e na floresta ombrófila densa (folhas de sombra), visando avaliar sua capacidade adaptativa para a implantação de estratégias de conservação in situ e ex situ.

\section{MATERIAL E MÉTODOS}

Folhas de indivíduos de Theobroma speciosum foram coletadas no Parque Nacional do Juruena e em pastagens na zona rural do município de Alta Floresta - MT. O parque apresenta uma área de 195.752.671 ha, com $60 \%$ no estado de Mato Grosso e $40 \%$ no de Amazonas (PARQUE NACIONAL DO JURUENA, 2013). É possível identificar na região a ocorrência de quatro grandes conjuntos de fisionomias: submontana, inter-montana, de terras baixas e riparia. Segundo a classificação de Köppen, a região apresenta clima tipo $A w i$, sendo tropical chuvoso com temperaturas médias entre 24 e $26^{\circ} \mathrm{C}$ e amplitude térmica anual de até $3^{\circ} \mathrm{C}$. As chuvas são abundantes (mais de $2.500 \mathrm{~mm}^{-1}$ ano e regulares (PARQUE NACIONAL DO JURUENA, 2013). O município de Alta Floresta, segundo a classificação de Köppen, apresenta clima tipo Awi sendo tropical chuvoso com estação seca nítida de dois meses. A temperatura média anual varia entre 20 e $38^{\circ} \mathrm{C}$, tendo média de $26^{\circ} \mathrm{C}$. A precipitação pluviométrica é elevada (entre 2.500 a $2.750 \mathrm{~mm}$ ), com intensidade máxima entre janeiro e março (FERREIRA, 2001).

As folhas de Theobroma speciosum no parque foram coletadas no mês de julho de $2012 \mathrm{e}$ as folhas na pastagem em março de 2013, as mesmas foram fixadas em FAA, com graduação alcoólica de $50^{\circ} \mathrm{GL}$, por $48 \mathrm{~h}$, sendo estocadas posteriormente em etanol $70^{\circ} \mathrm{GL}(70 \% \mathrm{~V} / \mathrm{v})(\mathrm{JOHANSEN}, 1940)$. Para a análise anatômica, foi escolhida a região mediana de folhas completamente desenvolvidas, ao nível do quinto nó visível de cinco indivíduos diferentes na área de pastagem e cinco na área de floresta. Secções transversais foram obtidas à mão livre, com o auxílio de lâmina de barbear, coradas com azul de astra e fucsina básica e montadas em lâminas histológicas (KAISER, 1980).

As ilustrações foram obtidas por meio do capturador de imagens, acoplado ao fotomicroscópio Leica DMLB, com o auxílio do programa Leica IM50.

Em seguida foi feita a caracterização anatômica das folhas e um estudo anatômico comparativo entre=folhas de árvores situadas na pastagem, expostas a uma maior intensidade luminosa, as quais foram chamadas "folhas de sol", e folhas de árvores localizadas no Parque, as quais foram denominadas "folhas de sombra", registrando-se as diferenças encontradas.

Foram analisados a espessura do mesofilo foliar, dos parênquimas paliçádico e lacunoso, da nervura mediana e do feixe vascular com o auxílio do programa Anati Quant $2 \mathbb{B}$ UFV (AGUIAR et al., 2007). Cada tratamento (folhas de sol e sombra) consistiu em 10 repetições, sendo cinco indivíduos e duas lâminas de cada. As médias da espessura de cada tecido foram comparadas pelo teste de Tukey a $5 \%$ de probabilidade pelo programa estatístico SISVAR 4.6 (FERREIRA, 2011). 
A estimação da divergência entre os 10 indivíduos de cacauí por meio de características anatômicas quantitativas foi realizada mediante o emprego de análise multivariada. Na predição da divergência, utilizouse a distância euclidiana média padronizada como medida de dissimilaridade (CRUZ; REGAZZI, 2001):

$$
D_{i i^{\prime}}=\sqrt{\frac{1}{n} \sum\left(\mathrm{X}_{i j}-\mathrm{X}_{i^{\prime} j}^{\prime}\right)^{2}}
$$

Em que Dii': distância entre os genótipos i e i'; Xij: observação no i-ésimo genitor em referência a j-ésima característica; n: número de características em estudo. A análise de agrupamento foi realizada mediante a utilização do método hierárquico UPGMA, com base na distância euclidiana média padronizada (CRUZ; REGAZZI, 2001), utilizando os recursos computacionais do Programa Genes (CRUZ, 2006).

\section{RESULTADOS E DISCUSSÃO}

Foram observados tricomas glandulares no limbo do tipo claviforme, com pedúnculo bicelular e cabeça com 4-6 células (Fig. 1A) e tricomas estrelados sésseis no limbo com elevação no centro do tricoma, na região basal (Fig. 1B). A presença destes apêndices foi considerada por Cuatrecasas (1964) como um caráter diagnóstico em Theobroma. Santos (2003) descreveu tricomas glandulares claviformes na epiderme cotiledonar de espécies de Theobroma, incluindo Theobroma speciosum, e Nakayama, Soares e AppezzatoDa-Glória (1996) nas folhas de Theobroma cacao.

A epiderme é unisseriada em secção transversal, com células mais altas de paredes periclinais externas geralmente planas na face adaxial, e células menores de paredes periclinais externas convexas na face abaxial (Fig. 1C).

O mesofilo da espécie é dorsiventral (Fig. 1C), característica comumente encontrada em Malvaceae (KUBITZKI; BAYER, 2003). O parênquima paliçádico consiste em um a dois estratos e o parênquima lacunoso=por três estratos de células alongadas (Fig. 1C), de modo que os parênquimas são pouco distintos.

Os feixes vasculares colaterais estão dispersos no mesofilo, envoltos por células esclerenquimáticas e parenquimáticas, com conteúdo fenólico, formando bainhas que se estendem até as epidermes (Fig. 1C). Tal característica também é verificada em Theobroma cacao (NAKAYAMA; SOARES; APPEZZATO-DAGLÓRIA, 1996).

Extensões da bainha do feixe são consideradas como vias de transporte de substâncias, principalmente água, entre as nervuras e as células epidérmicas (BECK, 2010).

Os ductos encontram-se associados aos feixes vasculares (Fig. 1C). Idioblastos, contendo cristais prismáticos ou comumente drusas de oxalato de cálcio, ocorrem geralmente entre as células do parênquima paliçádico (Fig. 1D). Segundo Franceschi e Nakata (2005), os cristais de oxalato de cálcio têm várias funções nos vegetais, como o armazenamento de cálcio, proteção contra herbivoria e regulação da luz durante a fotossíntese em plantas de ambiente de sombra.

A nervura central, em secção transversal, possui formato biconvexo (Fig. 1E). Logo abaixo da epiderme abaxial ocorrem cerca de duas a três camadas de colênquima angular-lacunar (Fig. 1B). Os resultados de Garcia (2012) corroboram com os encontrados em Theobroma speciosum aqui estudada, em estudo anatômico com três espécies nativas de Theobroma. A autora constatou que a morfologia da nervura central, em secção transversal, mostrou similaridade entre Theobroma grandiflorum e Theobroma subincanum, nas quais é côncava-convexa e variou em Theobroma speciosum, destacando-se como biconvexa. O sistema vascular apresenta-se fechado e envolto por bainha esclerenquimática. Os feixes vasculares são colaterais, geralmente organizados em forma de anel, com um ou mais feixes acessórios externos ou encerrados na medula (Fig. 1F). Na porção central da nervura observa-se um ducto secretor de mucilagem (Fig. 1E, 1F).

A constituição do mesofilo das folhas variou com o ambiente. Ambas as plantas apresentam parênquima paliçádico formado por uma camada de células, contudo as plantas expostas a pleno sol apresentam células mais alongadas (Fig. 2A). O parênquima lacunoso também se diferencia; nas folhas de sol apresenta muitas camadas de células com poucos espaços intercelulares, enquanto que as folhas de sombra apresentam células com muitos espaços intercelulares (Fig. 2B). As espessuras médias de ambos os tecidos apresentaram diferenças significativas. Os parênquimas paliçádico e lacunoso de plantas de sol 


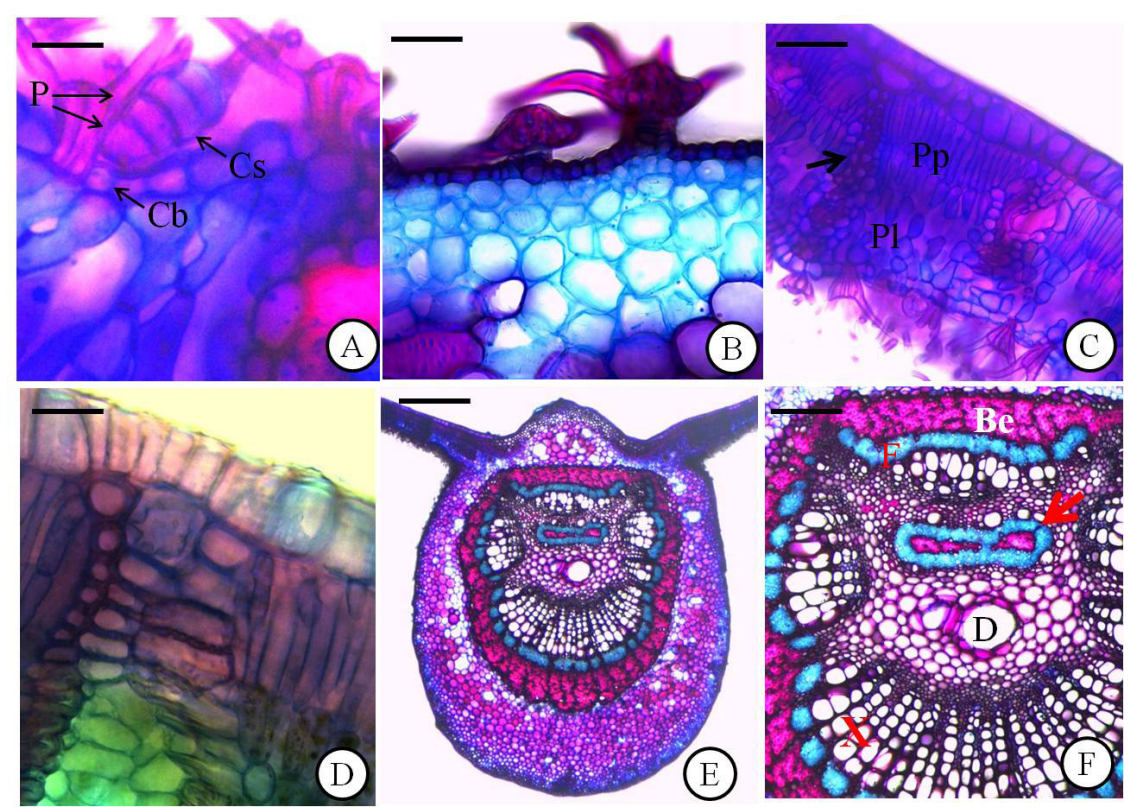

FIGURA 1: Secções transversais do limbo foliar de Theobroma speciosum. A: Tricoma glandular do tipo claviforme, constituído por célula basal $(\mathrm{Cb})$, pedúnculo bicelular $(\mathrm{P})$ e células secretoras (Cs). B: Tricoma estrelado pedunculado. C: Mesofilo, mostrando a estratificação dos parênquimas paliçádico $(\mathrm{Pp})$ e lacunoso $(\mathrm{Pl})$. Destaque para epiderme unisseriada e extensão da bainha parenquimática e esclerenquimática (seta preta). D: Idioblasto cristalífero em secção transversal. E: Aspecto geral da nervura central. F: Sistema vascular envolto por bainha esclerenquimática (Be), com arranjo em anel encerrando um feixe acessório na medula (seta), notar a ocorrência de ducto secretor (D) na porção central. X: xilema, F: floema. Barras: A: $40 \mu \mathrm{m}$; B e C: $50 \mu \mathrm{m}$; D: $80 \mu \mathrm{m}$; E: $110 \mu \mathrm{m}$; F: $60 \mu \mathrm{m}$.

FIGURE 1: Transverse sections of the leaf blade of Theobroma speciosum. A: Glandular trichomes of claviforme type, consisting of basal cell $(\mathrm{Cb})$, bicellular stalk $(\mathrm{P})$ and secretory cells $(\mathrm{Cs})$. B: Trichome starring. C: Mesophyll, showing the stratification of palisade (Pp) and spongy (Pl) parenchymas. Highlight for uniseriate epidermis and extent of parenchymal and sclerenchymatic sheath (black arrow). D: Idioblast in cross section. E: General view of central vein. F: Vascular system surrounded by sclerenchymatic sheath $(\mathrm{Be})$, arranged in ring enclosing a strand accessory spinal cord (arrow) noted the occurrence of secretory duct (D) in the central portion. X: xylem, F: phloem. Bars: A: $40 \mu \mathrm{m}$; B and C: $50 \mu \mathrm{m}$; D: $80 \mu \mathrm{m}$; E: $110 \mu \mathrm{m} ; \mathrm{F}: 60 \mu \mathrm{m}$.

apresentaram espessura média entre 392,2 e 429,9 $\mu \mathrm{m}$, já os tecidos das plantas de sombra apresentaram médias entre 238,4 e 228,2 $\mu \mathrm{m}$, respectivamente (Tabela 1).

Segundo Boeger e Wisniewski (2003), as folhas de árvores de florestas tropicais mais expostas à intensidade luminosa apresentam características xeromórficas, especialmente identificadas pelo parênquima paliçádico mais espesso, parênquima lacunoso com poucos espaços intercelulares e alto grau de esclerofilia, como observado no presente estudo (Tabela 1 e Fig. 2).

A maior espessura de parênquima paliçádico é importante para evitar a fotoinibição nas folhas com exposição a maior intensidade luminosa (TAIZ; ZEIGER, 2004). Isso permite que a luz seja transmitida mais diretamente, evitando o excesso de luz que incide na porção superior da árvore (MAJEROWICZ, 2004).

A maior razão da área dos espaços do parênquima lacunoso pela área total deste mesmo parênquima em folíolos de sombra (Fig. 2B) permite um maior aproveitamento da luz incidente na porção inferior interna do indivíduo, uma vez que os espaços intercelulares geram interfaces ar-água, que refletem e refratam a luz 
TABELA 1: Espessura da nervura central (NC), feixe vascular (FV), mesofilo (MS), parênquima paliçádico (PP) e parênquima lacunoso (PL), em folhas de Theobroma speciosum de pastagem (P) e de floresta ombrófila densa $(\mathrm{F})$.

TABLE 1: Thickness of the central rib (NC), vascular bundle (FV), mesophyll (MS), palisade parenchyma (PP) and spongy parenchyma (PL), in leaves of Theobroma speciosum pasture (P) and dense rain forest $(\mathrm{F})$.

\begin{tabular}{clllcc}
\hline \multirow{2}{*}{ Folhas } & \multicolumn{2}{c}{ NC } & \multicolumn{1}{c}{ FV } & MS & PP \\
\cline { 2 - 6 } & \multicolumn{3}{c}{$\mu \mathrm{m}$} \\
\hline Folha de Sol (P) & $2003,2 \mathrm{a}$ & $264,3 \mathrm{a}$ & $321,0 \mathrm{a}$ & $392,2 \mathrm{a}$ & $429,9 \mathrm{a}$ \\
Folha de Sombra (F) & $1516,7 \mathrm{~b}$ & $166,9 \mathrm{~b}$ & $206,5 \mathrm{~b}$ & $238,4 \mathrm{~b}$ & $228,2 \mathrm{~b}$ \\
\hline CV (\%) & 7,9 & 12,2 & 10,9 & 6,58 & 24,7 \\
\hline
\end{tabular}

Em que: Médias seguidas de mesma letra nas colunas não diferem entre si, pelo teste de Tukey, ao nível de 5\% de probabilidade de erro.
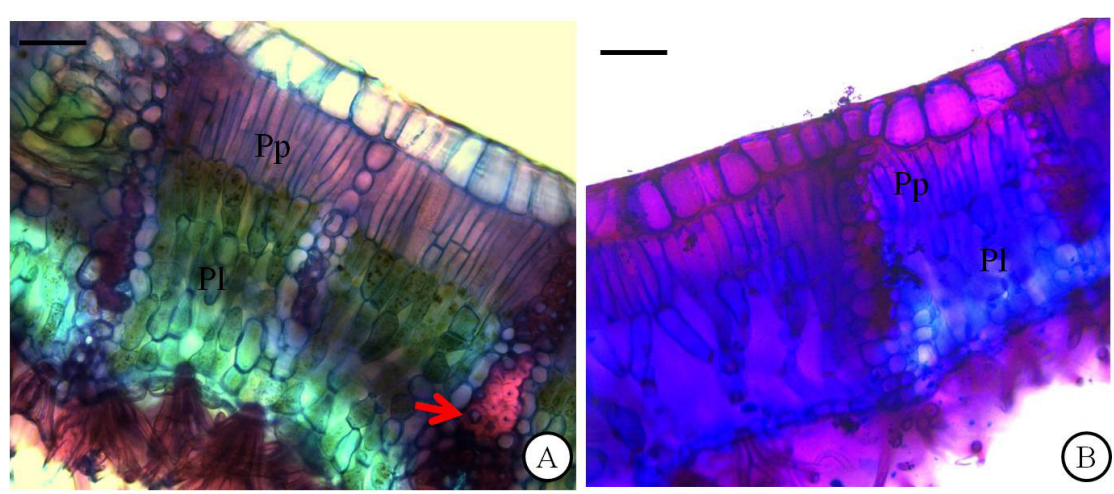

FIGURA 2: Secções transversais da folha de Theobroma speciosum. A: Mesofilo de folhas das plantas de ambiente a pleno sol, com feixes vasculares colaterais (seta). B: Mesofilo de folhas das plantas de ambiente sombreado. (Pl- Parênquima lacunoso; Pp- Parênquima paliçádico). Barras: A e B: $70 \mu \mathrm{m}$.

FIGURE 2: Transverse sections of the leaf Theobroma speciosum. A: Mesophyll of leaves of plants in full sun environment, with collateral vascular bundles (arrow). B: Mesophyll of leaves of plants in shaded environment (Pl- Spongy parenchyma, Pp - Palisade parenchyma). Bars: A and B: 70 micrometers.

possibilitando a difusão luminosa (MAJEROWICZ, 2004).

Outras características evidenciadas na Figura 2 é a presença em maior quantidade de tricomas nas folhas de sol e também maior espessura nos feixes vasculares colaterais (Fig. 2A). Segundo Waldhoff e Furch (2002) estas características também seriam especializações relacionadas à proteção, uma vez que os tricomas mantêm uma atmosfera saturada em vapor de água em torno da folha e os feixes vasculares são considerados vias de transporte principalmente para a água (LARCHER, 2000).

O dendrograma dos indivíduos pelo método UPGMA (Fig. 3), indica a formação de dois grupos principais. O grupo I é composto pelas plantas do Parque Nacional do Juruena (Indivíduos 1 a 5), enquanto que as plantas de ambiente a pleno sol (Pastagem) foram alocadas no grupo II (Indivíduos 6 a 10).

A característica quantitativa que mais contribuiu para a explicação da divergência anatômica entre as plantas de sol e de sombra foi a espessura da nervura central (69\%) (Tabela 2). As plantas de sol apresentaram uma média de 2003,2 $\mu \mathrm{m}$, enquanto as plantas de sombra 1516,7 (Tabela 1). Esse fato 


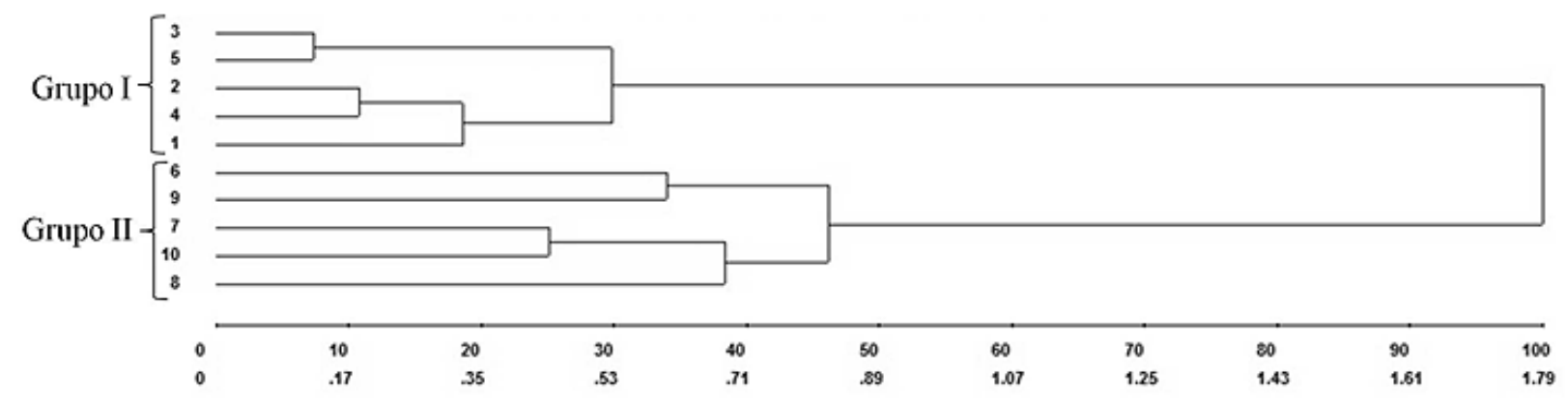

FIGURA 3: Dendrograma representativo do padrão de dissimilaridade entre os 10 indivíduos de Theobroma speciosum, obtido pelo método de agrupamento de ligação média entre grupos (UPGMA) com base na distância euclidiana média padronizada, estimada a partir de cinco características anatômicas quantitativas.

FIGURE 3: Dendrogram representative of the pattern of divergence among the 10 individuals of Theobroma speciosum, obtained by the method of grouping average connection between groups (UPGMA) based on standardized Euclidean distance average, estimated from five quantitative anatomical features.

corrobora com a observação feita por Eschrich (1995), de que os órgãos foliares melhor vascularizados (plantas de ambiente a pleno sol), tornam-se mais aptos a enfrentarem deficiências hídricas. Contudo, Gomes (1992) aponta que alguns estudos com espécies lenhosas indicam que mesmo aquelas plantas que na fase adulta são essencialmente heliófilas, apresentam um crescimento insatisfatório quando plantadas a pleno sol.

O agrupamento de plantas de sol e plantas de sombra em grupos distintos demonstrou alterações anatômicas significativas ocasionadas pelas variações da intensidade luminosa sobre as folhas, o que evidenciou grande capacidade adaptativa de Theobroma speciosum, uma vez que tal plasticidade permite a sobrevivência da espécie em ambientes diversos. Para o ambiente florestal, esta característica é fundamental, dada à dinâmica da floresta, e também justifica o desenvolvimento da espécie em áreas de pastagem.

A plasticidade fenotípica é a capacidade que alguns genótipos possuem de responder a alterações do meio ambiente em que se encontram, modificando a sua expressão fenotípica, mediante ajustamentos morfológicos e, ou fisiológicos (SCHLICHTING, 1986). No entanto, o seu maior interesse está relacionado com a possibilidade de a plasticidade incluir também processos ativos de adaptação ao stress ambiental. Este é um aspecto fundamental para garantir a estabilidade das populações perante as alterações globais do clima. É especialmente importante no caso das árvores, organismos de grande longevidade e reprodução

TABELA 2: Contribuição relativa das cinco características quantitativas avaliadas para a divergência anatômica foliar em 10 indivíduos de Theobroma speciosum.

TABLE 2: Relative contribution of the five qualitative characteristics evaluated for leaf anatomical divergence in 10 individuals of Theobroma speciosum.

\begin{tabular}{lc}
\hline \multicolumn{1}{c}{ Característica } & Contribuição (\%) \\
\hline Nervura Central & 69,1 \\
Parênquima lacunoso & 12,1 \\
Parênquima paliçádico & 7,95 \\
Feixe vascular & 6,82 \\
Mesofilo & 4,10 \\
\hline \multicolumn{2}{c}{ TOTAL } \\
\hline
\end{tabular}


tardia, incapazes de se deslocarem para zonas de clima mais favorável (SULTAN, 2000).

A capacidade adaptativa diante de diferentes condições de luminosidade evidencia que esta espécie pode obter sucesso em ambientes a céu aberto e sob cobertura, podendo inclusive ser usada em projetos de reflorestamento ou ainda em consórcio com outras espécies mais exigentes com relação à quantidade de luz. Contudo, são necessárias ainda, pesquisas que avaliem a germinação da espécie sob estresse hídrico, para verificar sua resiliência a ambientes secos, uma vez que os indivíduos isolados na pastagem, ora analisados, são provavelmente resultado de fragmentação florestal.

\section{CONCLUSÕES}

A epiderme das folhas de Theobroma speciosum é unisseriada, com mesofilo dorsiventral e parênquimas pouco distintos. Possui tricomas glandulares do tipo claviforme e tricomas estrelados sésseis. Feixes vasculares colaterais estão dispersos no mesofilo, formando bainhas que se estendem até as epidermes. A nervura central, em secção transversal, possui formato biconvexo, com sistema vascular fechado e envolto por bainha esclerenquimática.

A estrutura anatômica de Theobroma speciosum variou de acordo ao ambiente em que cresceu.

A espécie demonstrou capacidade adaptativa diante de diferentes condições de luminosidade, o que justifica estratégias de conservação in situ e ex situ.

\section{AGRADECIMENTOS}

Os autores agradecem a BIONORTE - MT (Projeto Conhecimento, uso sustentável e bioprospecção da biodiversidade na Amazônia Meridional - Processo: 554330/2010-5) contribuição n. ${ }^{\circ} 17$, PPBio (Projeto Inventário, conservação e valoração de alternativas sustentáveis do uso da biodiversidade na Amazônia Meridional - Processo: 558319/2009-2) e à CAPES pelo suporte financeiro.

\section{REFERÊNCIAS}

AGUIAR, T. V. et al. Anatquant: software de análises quantitativas para estudos em anatomia vegetal. Planta Daninha, Viçosa, MG, v. 25, n. 4, p. 649-659, 2007.

BECK, C. B. An introduction to plant structure and development plant. Anatomy for the Twenty-First Century. 2nd ed. New York: Cambridge University Press, 2010. 150 p.

BOEGER, M. R. T.; WISNIEWSKI, C. Comparação da morfologia foliar de espécies arbóreas de três estádios sucessionais distintos de floresta ombrófila densa (Floresta Atlântica) no Sul do Brasil. Revista Brasileira de Botânica, São Paulo, v. 26, n. 1, p. 61-72, 2003.

BOSABALIDIS, A. M.; KOFIDIS, G. Comparative effects of drought stress on leaf anatomy of two olive Cultivars. Plant Science, Davis, v. 163, p. 375-379, 2002.

CRUZ, C. D. Programa genes: biometria. Viçosa: Ed. da UFV, 2006. 220 p.

CRUZ, C. D.; REGAZZI, A. J. Divergência genética. In: CRUZ, C. D.; REGAZZI, A. J. (Ed.). Modelos biométricos aplicados ao melhoramento genético. Viçosa: Ed. da UFV, 2001. p. 287-324.

CUATRECASAS, J. Cacao and its allies: a taxonomic revision of the genus Theobroma. Contributions from the United State National Herbarium, Nova Iorque, v. 35, p. 579-614, 1964.

CUTTER, E. G. Plant anatomy: cells and tissues part I. London: William Clowes and Sons, 1978. p. 315-319.

DICKISON, W. C. Integrative Pant Anatomy. Burlington: Academic Press, 2000. 180 p.

ESCHRICH W. Funktionelle pflanzenantomie. Berlin: Springer-Verlag, 1995. 250 p.

FEARNSIDE, P. M. Soybean cultivation as a threat to the environment in Brazil. Environmental Conservation, Cambridge, v. 28, p. 23-38, 2001.

FERREIRA, D. F. Sisvar: a computer statistical analysis system. Ciência \&Agrotecnologia, Lavras, v. 35, n. 6, p. 1039-1042, 2011.

FERREIRA, J. C. V. Mato Grosso e seus Municípios. Cuiabá: Secretaria de Estado da Educação, 2001. $365 \mathrm{p}$. 
FRANCESCHI, V. R.; NAKATA, P. A. Calcium oxalate in plants: Formation and function. Annual Review of Plant Biology, Palo Alto. v. 56, p. 61-71, 2005.

GARCIA, T. B. Anatomia dos órgãos vegetativos aéreos de três espécies de Theobroma L. (Malvaceae) com ênfase nas estruturas secretoras: estrutura e histoquímica. 2012. 88 f. Dissertação (Mestrado em Ciências Biológicas - Botânica Tropical) - Universidade Federal Rural da Amazônia, Museu Paraense Emílio Goeldi, Belém, 2012.

GOMES, D. M. S. Anatomia foliar de Gomidesia spectabilis (DC) Berg. E G. nitida (Vell.) Legr. (Myrtaceae). Dissertação (Mestrado) - Universidade Federal do Rio de Janeiro, Rio de Janeiro, 1992. 66 p. JOHANSEN, D. A. Plant microtechnique. New York: MacGraw-Hill, 1940. 170 p.

KAISER, E. Verfahren zur Herstellung einer tadellosen Glycerin-Gelatine. Botanisch Zentralb, Berlin, v. 18, p. $25-26,1980$.

KUBITZKI, K.; BAYER, C. The families and genera of vascular plants. V. Flowering Plants. Dicotyledons. Malvales, Capparales and Non-betalain Caryophallales. Berlin: Springer, 2003. 550 p.

LARCHER, W. Ecofisiologia vegetal. São Paulo: Rima, 2000. 213 p.

LAURANCE, W. F.; VASCONCELOS, H. L. Consequências ecológicas da fragmentação florestal na amazônia. Oecologia Brasiliensis, Rio de Janeiro, v. 13, n. 3, p. 434-451, 2009.

LORENZI, H. Árvores Brasileiras: manual de identificação e cultivo de plantas arbóreas nativas do Brasil. Nova Odessa: Instituto Plantarum, 2000. 190 p.

LÜTTGE, U. Physiological ecology of tropical plants. Berlin: Springer-Verlag, 1997. 130 p.

MAJEROWICZ, N. Fotossíntese. In: KERBAUY, G. B. Fisiologia vegetal. Rio de Janeiro: Guanabara Koogan, 2004. p. 200-233.

MARTINI, M. H. et al. Localization of the cotyledon reserves of Theobroma grandiflorum (Willd. ex Spreng.) K. Schum., Theobroma subincanum Mart., Theobroma bicolor Bonpl. and their analogies with Theobroma cacao L. Revista Brasileira de Botânica, São Paulo, v. 31, n. 1, p. 147-154, 2008.

NAKAYAMA, L. H. I.; SOARES, M. K. M.; APPEZZATO-DA-GLÓRIA, B. Contribuição ao estudo anatômico da folha e do caule do cacaueiro (Theobroma cacao L.). Scientia Agricola, Piracicaba. v. 53, n. 1, p. 44-52, 1996.

PARQUE NACIONAL DO JURUENA. Parque Nacional do Juruena. [2013]. Disponível em: <http:// www.parquenacionaldojuruena.com.br>. Acesso em: 20 ago. 2013.

SANTOS, S. F. Estrutura e histoquímica de sementes do gênero Theobroma L. (Sterculiaceae). 2003. 77 f. Dissertação (Mestrado) - Universidade Federal de Santa Catarina, Florianópolis, 2003.

SCHLICHTING C. D. The evolution of phenotypic plasticity in plants. Annual Review of Ecology \& Systematics, Palo Alto, v. 17, p. 667-693, 1986.

SILVA, L. M.; ALQUINI, Y.; CAVALLET, V. J. Inter-relações entre a anatomia vegetal e a produção vegetal. Acta Botânica Brasílica, Belo Horizonte. v. 19, n.1, p. 183-194, 2005.

SULTAN S. E. Phenotypic plasticity for plant development, function, and life-history. Trends in Plant Science, Londres, v. 5, p. 537-542, 2000.

TAIZ, L.; ZEIGER, E. Fisiologia vegetal. 3. ed. Porto Alegre: Artmed, 2004. 245 p.

WALDHOFF, D.; FURCH, B. Leaf morphology and anatomy in eleven tree species from Central Amazonian floodplains (Brazil). Revista Amazoniana, Manaus. v. 17, n. 1, p. 79-94, 2002. 